\title{
Treatment Outcome of Wet Age-Related Macular Degeneration Management in Thailand: A Retrospective Real-World Study (TOWER Study)
}

\author{
Somanus Thoongsuwan · Prut Hanutsaha (D) · Yodpong Chantarasorn • \\ Paisan Ruamviboonsuk · Sritatath Vongkulsiri · Pavinee Kungwanpongpun
}

Received: December 13, 2021 / Accepted: January 26, 2022 / Published online: February 11, 2022

(C) The Author(s) 2022

\section{ABSTRACT}

Introduction: To present real-world outcomes of neovascular age-related macular degeneration (nAMD) management in Thailand.

Methods: This multicenter retrospective study reviewed medical records of naive nAMD patients diagnosed from 1 January 2016 until 31 December 2018. The patients received at least one intravitreal anti-vascular endothelial growth factor (VEGF) treatment and had

S. Thoongsuwan

Department of Ophthalmology, Faculty of

Medicine, Siriraj Hospital, Mahidol University,

Bangkok, Thailand

P. Hanutsaha $(\bowtie)$

Department of Ophthalmology, Faculty of Medicine

Ramathibodi Hospital, Mahidol University,

Bangkok, Thailand

e-mail: prut.han@mahidol.ac.th

Y. Chantarasorn

Department of Ophthalmology, Vajira Hospital,

Navamindradhiraj University, Bangkok, Thailand

P. Ruamviboonsuk

Department of Ophthalmology, Faculty of

Medicine, Rajavithi Hospital, Bangkok, Thailand

S. Vongkulsiri

Department of Ophthalmology, Phramongkutklao

Hospital, Phramongkutklao College of Medicine,

Bangkok, Thailand

P. Kungwanpongpun

Novartis (Thailand) Ltd., Bangkok, Thailand captured visual acuity (VA) at baseline and at month 12. Treatment outcomes were assessed at month 12,24 , and 36 . The primary outcome was a mean change in VA from baseline to month 12 .

Results: Five hundred seventy-two (572) eyes were included in this study and of these eyes, 222 and 96 had 2- and 3-year follow-up periods, respectively. At month 12, the mean improvement of VA (ETDRS letter) was six letters $(P<0.0001)$, and central retinal thickness (CRT) decreased on average by 104 microns $(P<0.0001)$. However, visual improvement by 0.1 letters at month 36 did not show statistical significance. The presence of fluid was found in approximately half of patients throughout the study period $(45.98 \%, 48.85 \%$, and $50.91 \%$ at month 12, 24, and 36, respectively). Mean number of injections (SD) was 6.06 (3.00), 3.44 (2.94), and 2.71 (3.07) for years 1, 2, and 3, respectively. The mean number of visits (SD) in year 1 was 9.01 (2.60) and declined to 5.67 (2.69) in year 2 and 4.93 (2.49) in year 3. Patients who had an average injection interval of $\leq 8$ weeks were $74.46 \%$ in year $1,51.28 \%$ in year 2 , and 45.24 in year $3 ; 35.31 \%$ of patients were lost to follow-up.

Conclusions: This analysis reflects real-world nAMD management with significant improvement of outcomes. At the same time, the study reveals unmet needs in anti-VEGF therapy in nAMD including persistent disease activities, inadequacy of available treatment, and lack of 
treatment adherence leading to visual deterioration in the long-term.

Keywords: Aflibercept; Anti-VEGF; Bevacizumab; nAMD; Neovascular age-related macular degeneration; Ranibizumab; Real-world study

\section{Key Summary Points}

Why carry out this study?

Neovascular age-related macular degeneration (nAMD) is one of the leading causes of permanent visual loss in elderly patients, and the gold standard treatment is intravitreal anti-vascular endothelial growth factor (anti-VEGF) treatment. Treatment outcomes in the real world differ from clinical studies because of various factors, e.g., patient characteristics, socioeconomics, etc.

We conducted this study to explore, for the first time to our knowledge, the outcomes and identify the unmet needs of nAMD management in Thailand, where polypoidal choroidal vasculopathy (PCV) frequently presents and the national health policy applies a stepwise anti-VEGF approach.

\section{What has been learned from the study?}

This analysis reflects real-world nAMD management with significant improvement of outcomes in year 1 but unmet needs including persistent disease activities and lack of treatment adherence leading to visual deterioration in the long term.

The study reveals unmet needs in antiVEGF therapy in nAMD, e.g., persistent disease activities or lack of treatment adherence. The novel modalities and patient adherence should be discussed and considered by patients and clinicians.

\section{INTRODUCTION}

Age-related macular degeneration (AMD) is one of the leading causes of permanent visual loss in elderly patients. Among the 33.6 million adults aged $\geq 50$ years who were blind in 2020 , AMD was found to be a cause in 1.8 million cases [1]. The first-line treatment for neovascular AMD (nAMD) is anti-vascular endothelial growth factor (VEGF) therapy. The evidence from clinical trials has vastly shown the superiority of anti-VEGF to other previous treatment modalities [2-4]. However, treatment regimens in landmark studies, monthly or bi-monthly injection, are less likely to be used in real-world practice. Clinicians favor a more flexible treatment posology, such as an "as needed" or a "treat-and-extend" regimen, which have shown impressive outcomes in many studies $[5,6]$. However, treatment outcomes in the real world are not like the results from clinical studies. Fewer treatments and hospital visits in the realworld result in less visual gains than those presented in most studies.

In Asians, polypoidal choroidal vasculopathy (PCV) is a common disease in patients presenting with serosanguinous maculopathy [7]. The prevalence of PCV in Thai patients who have a clinical presentation of choroidal neovascularization (CNV) has been reported as $77.50 \%$ [8], and improvement in visual outcomes after receiving anti-VEGF therapy has been shown in clinical trials $[9,10]$. However, suboptimal response to anti-VEGF therapy can be found in PCV and may lead to unfavorable long-term outcomes. In such cases, combined treatment with photodynamic therapy (PDT) may be considered.

In Thailand, bevacizumab, indicated for nAMD treatment, is the medication on the national drug list. For Medicare reimbursement, treatment of nAMD needs to be initiated with bevacizumab. More than $80 \%$ of Thai patients receive treatment under national health policy, and most of them cannot afford high-cost medications, i.e., ranibizumab, aflibercept, and PDT [11]. To the best of our knowledge, there has been no previous report on real-world outcomes of nAMD treatment in Thailand. 
Therefore, we conducted this study to explore the outcomes and identify the unmet needs of nAMD management in Thailand.

\section{METHODS}

We conducted a retrospective, multicenter, non-interventional real-world evidence study about the management of nAMD with antiVEGF therapy in Thailand. All data were extracted from medical records of five tertiary referral government hospitals. Patients included in the analysis were diagnosed with nAMD or PCV and were either treatment-naive or had not received anti-VEGF therapy within 6 months before the index date. All participants were $\geq$ 40 years old and were treated with intravitreal anti-VEGF therapy between 1 January 2016 and 31 December 2018, allowing at least 1 year of follow-up since starting the treatment. The study end date was 31 December 2019. All patients were required to have records of visual acuity (VA) at baseline and $12 \pm 2$ months of follow-up. We excluded eyes that received intraocular injections of other medications in the context of treatment intervention for nAMD. These patients had intraocular surgery within the first 12 months of anti-VEGF treatment. Eyes with other macular conditions as per the investigator, e.g., geographical atrophy, fibrosis, retinal vein occlusion, diabetic macular edema, diabetic retinopathy, or myopic choroidal neovascularization, were also excluded. If both eyes were eligible, the eye with less VA was included in the study. The study was approved by the ethics committee or institutional review board at each participating center and conducted in accordance with the Declaration of Helsinki. Patients' informed consent and consent to publish were exempted because of the retrospective nature of the study and use of unidentified retinal images and clinical data.

Patients were stratified based on treatment intensity into high and low intensity. High intensity was defined by receiving three loading doses in the first 3 months and having at least five anti-VEGF injections annually, whereas low intensity was defined by not receiving three loading doses in the first 3 months or having fewer than five anti-VEGF injections annually. Best-corrected visual acuity (BCVA) was tested using Snellen acuity charts and converted to Early Treatment Diabetic Retinopathy Study (ETDRS) letters. A zero (0) letter score was assigned to visual acuity of "counting fingers" to "no light perception."

The primary outcome was the mean change of VA from baseline to month 12 . Secondary outcomes included the mean change of VA from baseline to months 24 and 36, mean change of central retinal thickness (CRT) from baseline to month 12,24 , and 36, mean number of injections, and visits in each year. Moreover, the presence of fluid, which included intraretinal fluid (IRF), subretinal (SRF), pigment epithelial detachment (PED), and sub-retinal pigment epithelium fluid (sRPE), in optical coherence tomography (OCT) at baseline, months 12,24 , and 36 , was analyzed.

\section{Statistical Analysis}

Descriptive statistics were tabulated for demographic and clinical characteristics and outcome variables. These included means with standard deviations (SDs) and 95\% confidence intervals (CIs) for continuous variables. Categorical variables were summarized by providing counts and proportions, with 95\% CIs derived for all proportions. There was no imputation to account for missing, unused, or spurious data for this analysis. The proposed analyses were pooled but also separately conducted for nAMD patients with different treatment intensities. All analyses were performed by using SAS software version 9.4 (SAS Institute, Inc, Cary, NC). Outcome variables of mean change in VA and CRT from baseline to year 1,2 , and 3 were analyzed by using generalized estimating equations (GEEs) for repeated measures, and $P \leq 0.05$ was considered statistically significant. Exploratory analysis on comparison of mean change in VA and CRT between the high- and low-intensity treatment groups was performed by using independent $t$-test for normal distribution data or Wilcoxon rank-sum test for non-normal distribution data with $P \leq 0.05$ considered statistically significant. 
In terms of counts (number of injections, number of visits, proportion of patients with any particular mean treatment interval, proportion of patients with any fluids), the chisquare test was used. Fisher's exact test was used for small samples defined by expected value. Annualized rates were calculated by using GEE. The log of time on treatment in years was used as the offset variable. Huber-White (robust/ "sandwich") standard error estimates were used. All point estimates as well as the corresponding two-sided 95\% CIs were presented.

\section{RESULTS}

\section{Patient Characteristics}

A total of 4840 eyes were diagnosed as nAMD with at least one anti-VEGF injection from 1 January 2016 to 31 December 2018. Of these eyes, 601 eyes were treatment naive or had received anti-VEGF therapy $>6$ months before the index date. Twenty-nine patients were excluded from the study because of the lack of VA data at $12 \pm 2$ months.

Finally, 572 patients were enrolled in this study. Patient disposition in this cohort study is shown in Fig. 1. Focusing on time of enrollment, the number of patients registered into the study was not distinctive in each year $(28.67 \%$, $31.12 \%$, and $40.21 \%$ in year 1,2 , and 3 , respectively). Several loss to follow-up cases, defined as patients who had a follow-up period $<3$ years and lack of follow-up visits for $>$ 6 months before the end of the study, were investigated. In total, 202 of 572 patients (35.31\%) were identified as lost to follow-up. The number of patients enrolled and loss to follow-up from month 1 to 36 is illustrated in Fig. 2.

The average age of patients was 68.64 years. Two hundred fifty-seven patients (44.93\%) were female. Overall, the eye diagnosed with nAMD/ PCV and included in the cohort at baseline was the right eye for $52.97 \%$ of the patients; $42.13 \%$ and $57.87 \%$ of patients were diagnosed with nAMD and PCV, respectively.

Baseline characteristics of our study cohort are presented in Table 1.
Imaging investigations performed at baseline were fundus fluorescein angiography (FFA) $39.86 \%$, indocyanine green angiography (ICGA) $39.34 \%$, OCT $85.84 \%$, and color fundus photo $33.92 \%$ (Table 2).

Most of our patients (78.50\%) initiated treatment with bevacizumab, and 266 of 572 $(46.50 \%)$ were treated with bevacizumab without switching to other agents. A total of 183 (31.99\%) of 572 patients switched therapy from bevacizumab to other anti-VEGF agents. Switching to aflibercept was the most common pattern, which comprised $30 \%$ of the patients in our study. Only $52(9.09 \%)$ of all patients were exposed to at least one PDT (Table 3).

\section{Visual Outcomes}

The average of baseline VA (mean) was 43.6 letters (equivalent to 20/125 Snellen equivalent), and the proportion of patients having VA worse than $20 / 50$ was $69.93 \%$. At month 12 , mean improvement of VA was 6 letters compared to baseline $(P<0.0001)$. The analysis also revealed visual gains at month 24 by 5 letters $(P=0.0026)$. However, VA improvement by 0.1 letters at month 36 did not show statistical significance (Fig. 3, Table 4).

\section{Anatomical Outcomes}

The mean (SD) CRT was 419.62 (192.08) microns. After anti-VEGF therapy, anatomical improvement was found with a mean reduction of $104.03(P<0.0001), 105.67 \quad(P<0.0001)$, and $64.89(P=0.0122)$ microns at year 1 $(n=305), 2(n=67)$, and $3(n=27)$, respectively, compared to baseline CRT (Table 5, Figs. 4 and 5).

Disease activity after treatment, which is represented by the presence of IRF, SRF, or sRPE on OCT images, was detected in approximately half of patients throughout the study period $(45.98 \%, 48.85 \%$, and $50.91 \%$ at month 12,24 , and 36 , respectively).

The anatomical outcomes of the patients who received injections at high intensity were better than in patients on low-intensity injections. The mean change in CRT compared to 


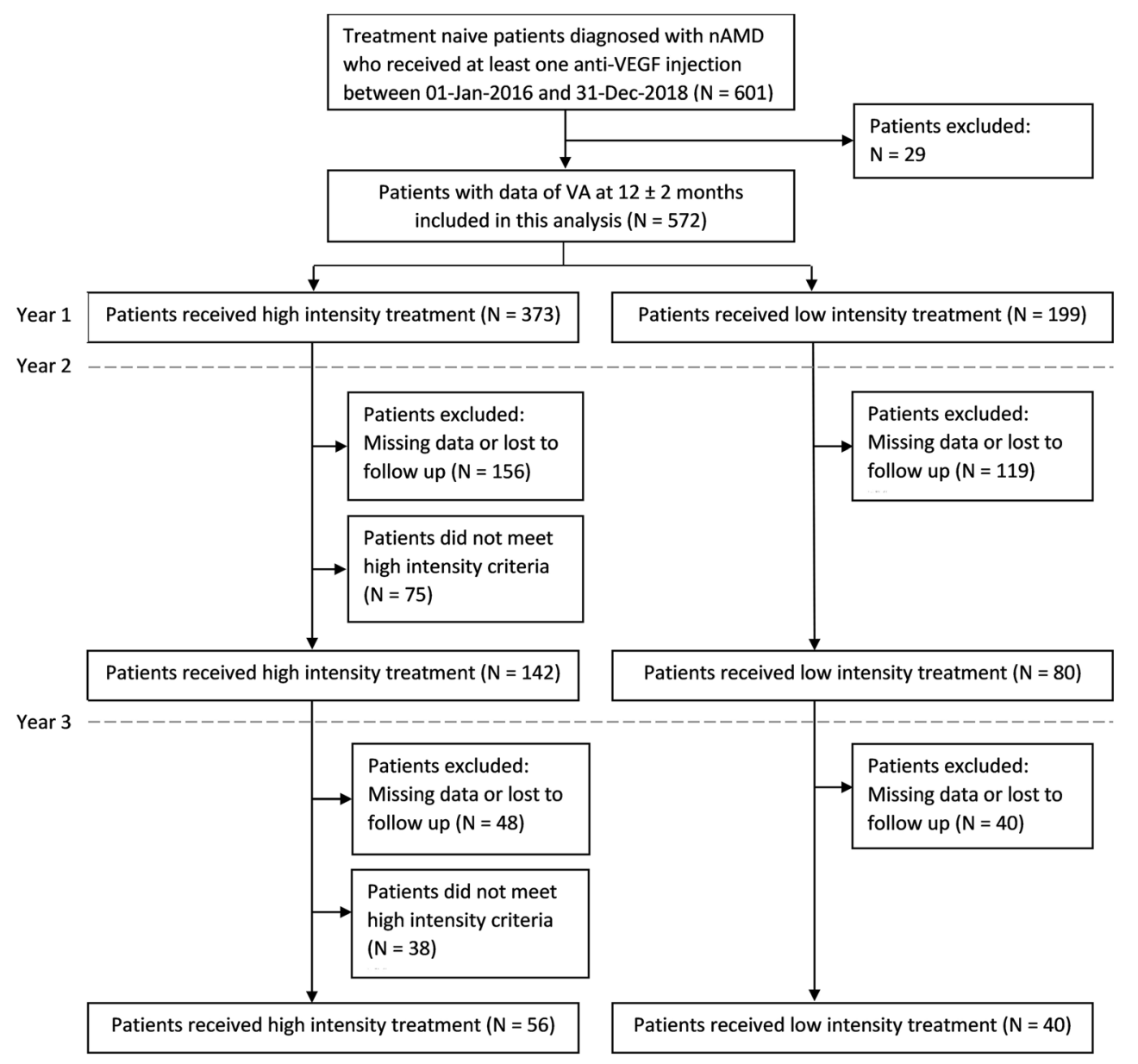

Fig. 1 Patient disposition in this cohort study

baseline in the high-intensity group was greater but not statistically significant compared with the low-intensity group at any time point of the study (Fig. 5).

Focusing on disease activity, the proportion of patients having disease activity in the highintensity group was higher than for patients in the low-intensity group $(52.28 \%$ vs. $34.17 \%$ in year $1,61.29 \%$ vs. $37.68 \%$ in year 2 , and $77.78 \%$ vs. $37.84 \%$ in year 3) (Fig. 6).

\section{Treatment Burden}

The mean (SD) number of injections administered in year 1, 2, and 3 was 6.06 (3.00), 3.44 (2.94), and $2.71(3.07)$, respectively. The mean
(SD) number of visits in year 1 was 9.01 (2.60) and declined to 5.67 (2.69) in year 2 and further to 4.93 (2.49) in year 3 .

In the first 12 months, $74.46 \%$ of patients had a mean injection interval $\leq 8$ weeks. The proportion of patients who had a mean injection interval $>12$ weeks in years 2 and 3 was $22.22 \%$ and $21.43 \%$, respectively (Fig. 7).

\section{Safety Outcomes}

The incidence of serious adverse events in our study was $0.35 \% \quad(n=2)$. One patient had endophthalmitis related to ranibizumab injection, and the other had a stroke. Both patients were in the high-intensity group. 


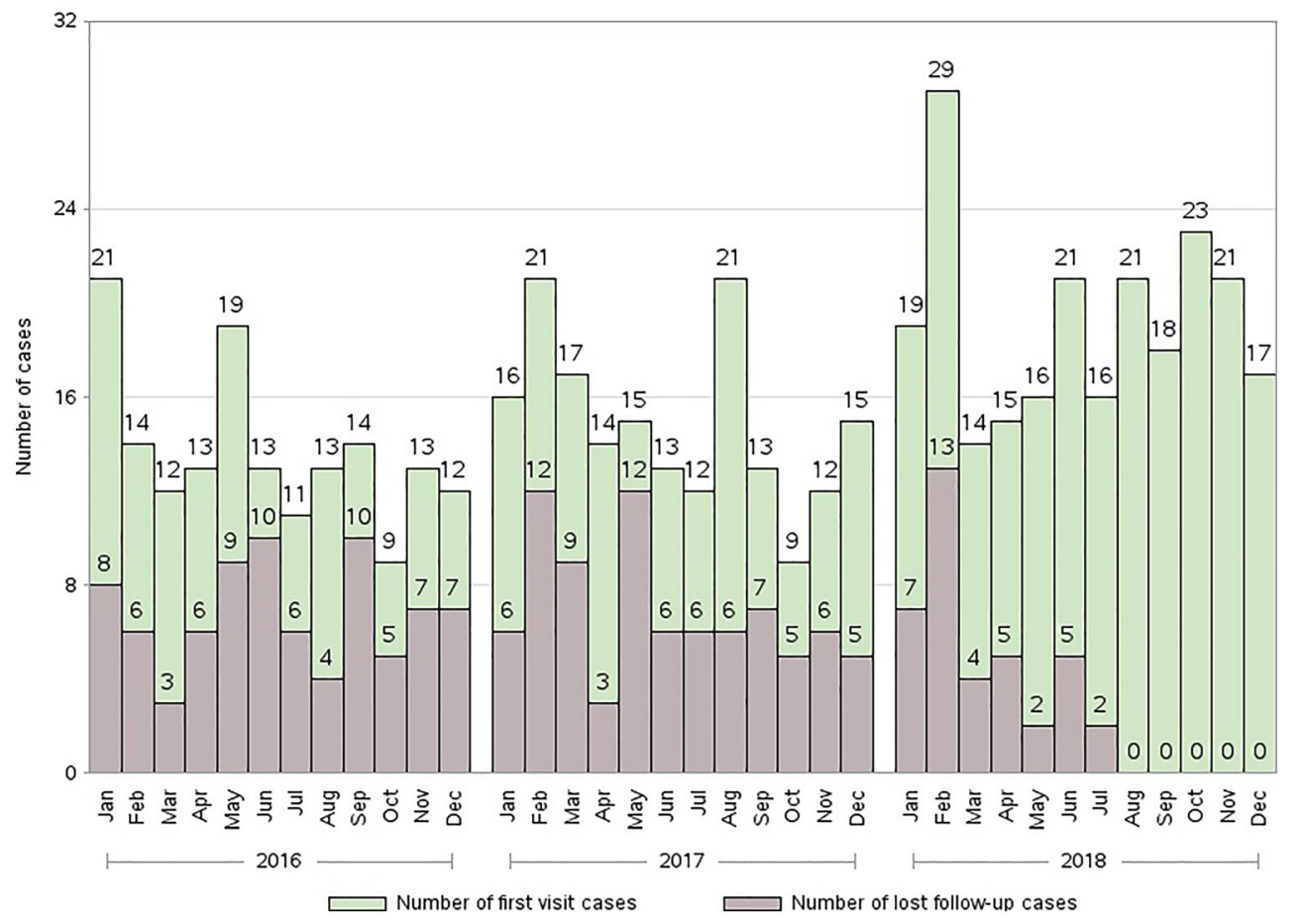

Fig. 2 Number of patients enrolled and lost to follow-up from 1 to 36 months. Green bars show time of enrollment by month. Gray bars show the number of lost follow-up

\section{DISCUSSION}

Management of nAMD in the context of reallife practice is different from clinical studies. The diagnosis in general practice is more likely to use clinical findings together with noninvasive investigations such as OCT. In our study, FFA and ICGA were performed in only $40 \%$ of patients at baseline, while OCT imaging was performed in $>80 \%$ of patients. The advance in imaging technology helps to understand the pathophysiology of nAMD and PCV distinctly. Noninvasive imaging techniques such as OCT are practical and suitable for use in clinical practice. The characteristics in OCT images are specific and help in the diagnosis of nAMD [12]. In the real world, when elderly patients with multiple drusen in the macula and OCT revealed signs of exudations accompanied by RPE elevation or disruption, the diagnosis of nAMD is highly suggested. Anti-VEGF therapy can be initiated while using OCT for monitoring treatment response with no need to perform cases defined as patients who had a follow-up period for $<$ 3 years and lack of follow-up visit for $>6$ months prior to the end of the study

angiography. Recently, the Asia-Pacific Ocular Imaging Society proposed practical diagnostic criteria using findings on spectral-domain OCT, i.e., sub-RPE ring-like lesion, sharp peaked PED, and en face OCT complex RPE elevation, for diagnosis of PCV with high accuracy [13].

Visual outcomes of nAMD patients have been improved after the introduction of antiVEGF treatments in the early 2000s. Anti-VEGF therapies have become a first-line treatment for treating and stabilizing nAMD as recommended in universal practice guidelines [14-17]. The drawbacks of anti-VEGF therapy include the necessity of repeated injections and regular long-term monitoring to maintain visual acuity. However, the outcomes from real-world studies compared with those from clinical trials, are still different based on the impact of undertreatment $[18,19]$.

In our study, nAMD patients achieved an improvement in visual and anatomical outcomes after receiving anti-VEGF therapy. At month 12 , the average gain of vision was 5.97 
Table 1 Baseline characteristics of patients included in the study cohort

\begin{tabular}{|c|c|c|c|c|}
\hline \multirow[t]{2}{*}{ Characteristics } & \multirow{2}{*}{$\begin{array}{l}\text { Total }(N=572) \\
n(\%)(95 \% \mathrm{CI})\end{array}$} & \multicolumn{2}{|l|}{ Treatment intensity } & \multirow[t]{2}{*}{$P$ value } \\
\hline & & $\begin{array}{l}\text { High intensity } \\
(N=373) \\
n(\%)(95 \% \mathrm{CI})\end{array}$ & $\begin{array}{l}\text { Low intensity } \\
(N=199) \\
n(\%)(95 \% \mathrm{CI})\end{array}$ & \\
\hline \multicolumn{5}{|l|}{ Demographics } \\
\hline \multicolumn{4}{|l|}{ Gender } & $0.7791^{[1]}$ \\
\hline \multirow[t]{2}{*}{ Male } & $315(55.07 \%)$ & $207(55.50 \%)$ & $108(54.27 \%)$ & \\
\hline & $(50.99-59.15)$ & $(50.45-60.54)$ & $(47.35-61.19)$ & \\
\hline \multirow[t]{2}{*}{ Female } & $257(44.93 \%)$ & $166(44.50 \%)$ & $91(45.73 \%)$ & \\
\hline & $(40.85-49.01)$ & $(39.46-49.55)$ & $(38.81-52.65)$ & \\
\hline \multicolumn{2}{|l|}{ Age (years) } & & & $0.8620^{[3]}$ \\
\hline $\mathrm{N}$ & 572 & 373 & 199 & \\
\hline Mean (SD) & $68.64(10.24)$ & $68.62(9.83)$ & $68.67(11.00)$ & \\
\hline$(95 \% \mathrm{CI})$ & $(67.80-69.48)$ & $(67.62-69.62)$ & $(67.13-70.21)$ & \\
\hline Median (Q1-Q3) & $\begin{array}{l}68.00 \\
\quad(61.00-76.00)\end{array}$ & $68.00(62.00-76.00)$ & $67.00(60.00-77.00)$ & \\
\hline Min-max & $40-99$ & $40-99$ & $40-96$ & \\
\hline \multicolumn{2}{|l|}{ Ethnicity } & & & $1.0000^{[2]}$ \\
\hline \multirow[t]{2}{*}{ Caucasian } & $2(0.35 \%)$ & $1(0.27 \%)$ & $1(0.50 \%)$ & \\
\hline & $(0.00-0.83)$ & $(0.00-0.79)$ & $(0.00-1.48)$ & \\
\hline \multirow[t]{2}{*}{ Black } & $0(0.00 \%)$ & $0(0.00 \%)$ & $0(0.00 \%)$ & \\
\hline & $(0.00-0.00)$ & $(0.00-0.00)$ & $(0.00-0.00)$ & \\
\hline \multirow[t]{2}{*}{ Asian } & $570(99.65 \%)$ & $372(99.73 \%)$ & $198(99.50 \%)$ & \\
\hline & $(99.17-100.00)$ & $(99.21-100.00)$ & $(98.52-100.00)$ & \\
\hline \multirow[t]{2}{*}{ Other, specify } & $0(0.00 \%)$ & $0(0.00 \%)$ & $0(0.00 \%)$ & \\
\hline & $(0.00-0.00)$ & $(0.00-0.00)$ & $(0.00-0.00)$ & \\
\hline \multicolumn{2}{|l|}{ Study eye } & & & $0.6493^{[1]}$ \\
\hline \multirow[t]{2}{*}{ Left } & $269(47.03 \%)$ & $178(47.72 \%)$ & $91(45.73 \%)$ & \\
\hline & $(42.94-51.12)$ & $(42.65-52.79)$ & $(38.81-52.65)$ & \\
\hline \multirow[t]{2}{*}{ Right } & $303(52.97 \%)$ & $195(52.28 \%)$ & $108(54.27 \%)$ & \\
\hline & $(48.88-57.06)$ & $(47.21-57.35)$ & $(47.35-61.19)$ & \\
\hline \multicolumn{2}{|l|}{ Diagnosis } & & & $0.3594^{[1]}$ \\
\hline \multirow[t]{2}{*}{ nAMD } & $241(42.13 \%)$ & $152(40.75 \%)$ & $89(44.72 \%)$ & \\
\hline & $(38.09-46.18)$ & $(35.76-45.74)$ & $(37.82-51.63)$ & \\
\hline PCV & $331(57.87 \%)$ & $221(59.25 \%)$ & $110(55.28 \%)$ & \\
\hline
\end{tabular}


Table 1 continued

\begin{tabular}{|c|c|c|c|c|}
\hline \multirow[t]{2}{*}{ Characteristics } & \multirow{2}{*}{$\begin{array}{l}\text { Total }(N=572) \\
n(\%)(95 \% \mathrm{CI})\end{array}$} & \multicolumn{2}{|c|}{ Treatment intensity } & \multirow[t]{2}{*}{$P$ value } \\
\hline & & $\begin{array}{l}\text { High intensity } \\
(N=373) \\
n(\%)(95 \% \mathrm{CI})\end{array}$ & $\begin{array}{l}\text { Low intensity } \\
(N=199) \\
n(\%)(95 \% \mathrm{CI})\end{array}$ & \\
\hline & $(53.82-61.91)$ & $(54.26-64.24)$ & $(48.37-62.18)$ & \\
\hline \multicolumn{5}{|l|}{ Ocular characteristics } \\
\hline \multicolumn{5}{|l|}{ VA (ETDRS letter) } \\
\hline$N$ & 572 & 373 & 199 & \\
\hline Mean (SD) & $43.56(25.92)$ & $45.71(24.59)$ & $39.52(27.85)$ & $0.0172^{[3]}$ \\
\hline$(95 \% \mathrm{CI})$ & $(41.43-45.69)$ & $(43.21-48.21)$ & $(35.63-43.42)$ & \\
\hline Subgroup & & & & $0.8724^{[1]}$ \\
\hline \multirow{2}{*}{$\begin{array}{l}<20 / 50 \text {, equivalent } \\
\text { letters }\end{array}$} & $400(69.93 \%)$ & $260(69.71 \%)$ & $140(70.35 \%)$ & \\
\hline & $(66.17-73.69)$ & $(65.04-74.37)$ & $(64.01-76.70)$ & \\
\hline \multirow{2}{*}{$\begin{array}{l}\geq 20 / 50 \text {, equivalent to } \geq 69 \text { ETDRS } \\
\text { letters }\end{array}$} & $172(30.07 \%)$ & $113(30.29 \%)$ & $59(29.65 \%)$ & \\
\hline & $(26.31-33.83)$ & $(25.63-34.96)$ & $(23.30-35.99)$ & \\
\hline \multicolumn{5}{|l|}{ CRT from OCT $(\mu \mathrm{m})$} \\
\hline$N$ & 398 & 263 & 135 & \\
\hline Mean (SD) & $419.62(192.08)$ & $413.77(181.47)$ & $431.03(211.49)$ & $0.8822^{[3]}$ \\
\hline (95\% CI) & $(400.69-438.55)$ & $(391.73-435.80)$ & (395.03-467.03) & \\
\hline
\end{tabular}

letters, which is greater than outcomes from previous reports. The improvement of 2 letters and 2.4 letters at year 1 was demonstrated in real-world studies in Europe and the UK, respectively [20, 21]. The authors postulated that the reduced number of treatments in real clinical practice was a leading cause of poor outcomes. In the first year, the average number of injections and visits in our study was quite high (6.06 injections and 9.01 visits). Our study was conducted in 2016-2018, and during that time, the trend of nAMD treatment transitioned to treat and extend, which is a proactive regimen that resulted in more treatments and better outcomes compared to an as-needed regimen that was formerly commonly used in real-world practice [22].

Moreover, anti-VEGF treatment in Thailand is accessible for all nAMD patients because bevacizumab is covered by the government Medicare. This national health policy reduced the treatment barrier and helped patients to access affordable standard treatment for nAMD. However, pharmacokinetic properties of bevacizumab demonstrated a lower binding affinity to VEGF-A molecules than other anti-VEGF agents [23]. By using bevacizumab, patients may need injections and monitoring more 
Table 2 Imaging investigation modalities at baseline

\begin{tabular}{|c|c|c|c|c|}
\hline \multirow[t]{2}{*}{ Diagnostics } & \multirow{2}{*}{$\begin{array}{l}\text { Total } \\
n(\%)(95 \% \mathrm{CI})\end{array}$} & \multicolumn{2}{|c|}{ Treatment intensity } & \multirow[t]{2}{*}{$P$ value } \\
\hline & & $\begin{array}{l}\text { High intensity } \\
n(\%)(95 \% \mathrm{CI})\end{array}$ & $\begin{array}{l}\text { Low intensity } \\
n(\%)(95 \% \text { CI })\end{array}$ & \\
\hline Baseline & $N=572$ & $N=373$ & $N=199$ & \\
\hline FFA & $\begin{array}{l}228(39.86 \%) \\
(35.85-43.87)\end{array}$ & $\begin{array}{l}158(42.36 \%) \\
(37.34-47.37)\end{array}$ & $\begin{array}{l}70(35.18 \%) \\
(28.54-41.81)\end{array}$ & $0.0947^{[1]}$ \\
\hline IGCA & $\begin{array}{l}225(39.34 \%) \\
(35.33-43.34)\end{array}$ & $\begin{array}{l}157(42.09 \%) \\
(37.08-47.10)\end{array}$ & $\begin{array}{l}68(34.17 \%) \\
(27.58-40.76)\end{array}$ & $0.0647^{[1]}$ \\
\hline OCT & $\begin{array}{l}491(85.84 \%) \\
(82.98-88.70)\end{array}$ & $\begin{array}{l}326(87.40 \%) \\
(84.03-90.77)\end{array}$ & $\begin{array}{l}165(82.91 \%) \\
(77.69-88.14)\end{array}$ & $0.1428^{[1]}$ \\
\hline Color fundus photo & $\begin{array}{l}194(33.92 \%) \\
(30.04-37.80)\end{array}$ & $\begin{array}{l}114(30.56 \%) \\
(25.89-35.24)\end{array}$ & $\begin{array}{l}80(40.20 \%) \\
(33.39-47.01)\end{array}$ & $0.0204^{[1] *}$ \\
\hline Month 12 & $N=572$ & $N=373$ & $N=199$ & \\
\hline FFA & $\begin{array}{l}19(3.32 \%) \\
(1.85-4.79)\end{array}$ & $\begin{array}{l}13(3.49 \%) \\
(1.62-5.35)\end{array}$ & $\begin{array}{l}6(3.02 \%) \\
(0.64-5.39)\end{array}$ & $0.7650^{[1]}$ \\
\hline IGCA & $\begin{array}{l}19(3.32 \%) \\
(1.85-4.79)\end{array}$ & $\begin{array}{l}13(3.49 \%) \\
(1.62-5.35)\end{array}$ & $\begin{array}{l}6(3.02 \%) \\
(0.64-5.39)\end{array}$ & $0.7650^{[1]}$ \\
\hline OCT & $\begin{array}{l}438(76.57 \%) \\
(73.10-80.04)\end{array}$ & $\begin{array}{l}298(79.89 \%) \\
(75.83-83.96)\end{array}$ & $\begin{array}{l}140(70.35 \%) \\
(64.01-76.70)\end{array}$ & $0.0103^{[1]^{*}}$ \\
\hline Color fundus photo & $\begin{array}{l}105(18.36 \%) \\
(15.18-21.53)\end{array}$ & $\begin{array}{l}61(16.35 \%) \\
(12.60-20.11)\end{array}$ & $\begin{array}{l}44(22.11 \%) \\
(16.34-27.88)\end{array}$ & $0.0903^{[1]}$ \\
\hline Month 24 & $N=206$ & $N=62$ & $N=144$ & \\
\hline FFA & $\begin{array}{l}5(2.43 \%) \\
(0.33-4.53)\end{array}$ & $\begin{array}{l}2(3.23 \%) \\
(0.00-7.62)\end{array}$ & $\begin{array}{l}3(2.08 \%) \\
(0.00-4.42)\end{array}$ & $0.6382^{[2]}$ \\
\hline IGCA & $\begin{array}{l}5(2.43 \%) \\
(0.33-4.53)\end{array}$ & $\begin{array}{l}2(3.23 \%) \\
(0.00-7.62)\end{array}$ & $\begin{array}{l}3(2.08 \%) \\
(0.00-4.42)\end{array}$ & $0.6382^{[2]}$ \\
\hline OCT & $\begin{array}{l}161(78.16 \%) \\
(72.51-83.80)\end{array}$ & $\begin{array}{l}53(85.48 \%) \\
(76.72-94.25)\end{array}$ & $\begin{array}{l}108(75.00 \%) \\
(67.93-82.07)\end{array}$ & $0.0948^{[1]}$ \\
\hline Color fundus photo & $\begin{array}{l}34(16.50 \%) \\
(11.44-21.57)\end{array}$ & $\begin{array}{l}6(9.68 \%) \\
(2.32-17.04)\end{array}$ & $\begin{array}{l}28(19.44 \%) \\
(12.98-25.91)\end{array}$ & $0.0833^{[1]}$ \\
\hline Month 36 & $N=93$ & $N=18$ & $N=75$ & \\
\hline FFA & $\begin{array}{l}1(1.08 \%) \\
(0.00-3.17)\end{array}$ & $\begin{array}{l}0(0.00 \%) \\
(0.00-0.00)\end{array}$ & $\begin{array}{l}1(1.33 \%) \\
(0.00-3.93)\end{array}$ & $1.0000^{[2]}$ \\
\hline IGCA & $1(1.08 \%)$ & $0(0.00 \%)$ & $1(1.33 \%)$ & $1.0000^{[2]}$ \\
\hline
\end{tabular}


Table 2 continued

\begin{tabular}{|c|c|c|c|c|}
\hline \multirow[t]{2}{*}{ Diagnostics } & \multirow{2}{*}{$\begin{array}{l}\text { Total } \\
n(\%)(95 \% \mathrm{CI})\end{array}$} & \multicolumn{2}{|c|}{ Treatment intensity } & \multirow[t]{2}{*}{$P$ value } \\
\hline & & $\begin{array}{l}\text { High intensity } \\
n(\%)(95 \% \mathrm{CI})\end{array}$ & $\begin{array}{l}\text { Low intensity } \\
n(\%)(95 \% \text { CI })\end{array}$ & \\
\hline & $(0.00-3.17)$ & $(0.00-0.00)$ & $(0.00-3.93)$ & \\
\hline \multirow[t]{2}{*}{ OCT } & $79(84.95 \%)$ & $16(88.89 \%)$ & $63(84.00 \%)$ & $1.0000^{[2]}$ \\
\hline & $(77.68-92.21)$ & $(74.37-100.00)$ & $(75.70-92.30)$ & \\
\hline \multirow[t]{2}{*}{ Color fundus photo } & $18(19.35 \%)$ & $1(5.56 \%)$ & $17(22.67 \%)$ & $0.1804^{[2]}$ \\
\hline & $(11.33-27.38)$ & $(0.00-16.14)$ & $(13.19-32.14)$ & \\
\hline
\end{tabular}

Patients had data on investigation modalities

${ }^{[1]}$ Overall $P$ value (2-sided) based on chi-square test

${ }^{[2]}$ Overall $P$ value (2-sided) based on Fisher's exact test

${ }^{*} P \leq 0.05$ is considered statistically significant

Table 3 Treatment modalities for patients with captured visual acuity (VA)

\begin{tabular}{llll}
\hline Treatment posology & & \multicolumn{1}{l}{$\boldsymbol{N ( \% ) ^ { * }}$} \\
\hline $\begin{array}{l}\text { Anti-VEGF monotherapy } \\
\text { Anti-VEGF combined with photodynamic therapy }\end{array}$ & & & $520(90.90 \%)$ \\
\hline First anti-VEGF before first switching & Aflibercept & Ranibizumab & Bevacizumab \\
\hline$N(\%)^{*}$ & $98(17.13 \%)$ & $25(4.37 \%)$ & $449(78.50 \%)$ \\
Mean no. of injections (SD) & $5.35(3.83)$ & $3.56(3.25)$ & $5.12(3.32)$ \\
Mean duration of treatment (months) (SD) & $10.69(10.08)$ & $5.68(5.48)$ & $9.02(8.49)$ \\
Switching to* & & & \\
Aflibercept, $n(\%)$ & $60(61.22 \%)^{* * *}$ & $15(60.00 \%)$ & $158(35.19 \%)$ \\
Ranibizumab, $n(\%)$ & $10(10.20 \%)$ & $5(20.00 \%)^{* * *}$ & $22(4.90 \%)$ \\
Bevacizumab, $n(\%)$ & $28(28.57 \%)$ & $5(20.00 \%)$ & $266(59.24 \%)^{* * *}$ \\
ZIV-aflibercept, $n(\%)$ & $0(0.00 \%)$ & $0(0.00 \%)$ & $3(0.67 \%)$ \\
\hline
\end{tabular}

*All percentages were calculated from a total number of subjects $(N=572)$

${ }^{* *}$ All perentages of first switching were calculated from total number of first anti-VEGF

${ }^{* * *}$ No switching

frequently. A previous study investigating outcomes of nAMD management with bevacizumab first-line policy, as required by the Dutch guideline, showed that the median number of injections and visits was significantly higher in The Netherlands than in other countries participating in the Fight Retinal Blindness Registry [24]. The TOWER study is the first to investigate real-world outcomes of nAMD management in emerging countries applying the policy. Similarly, among patients who received more than one injection [24], 


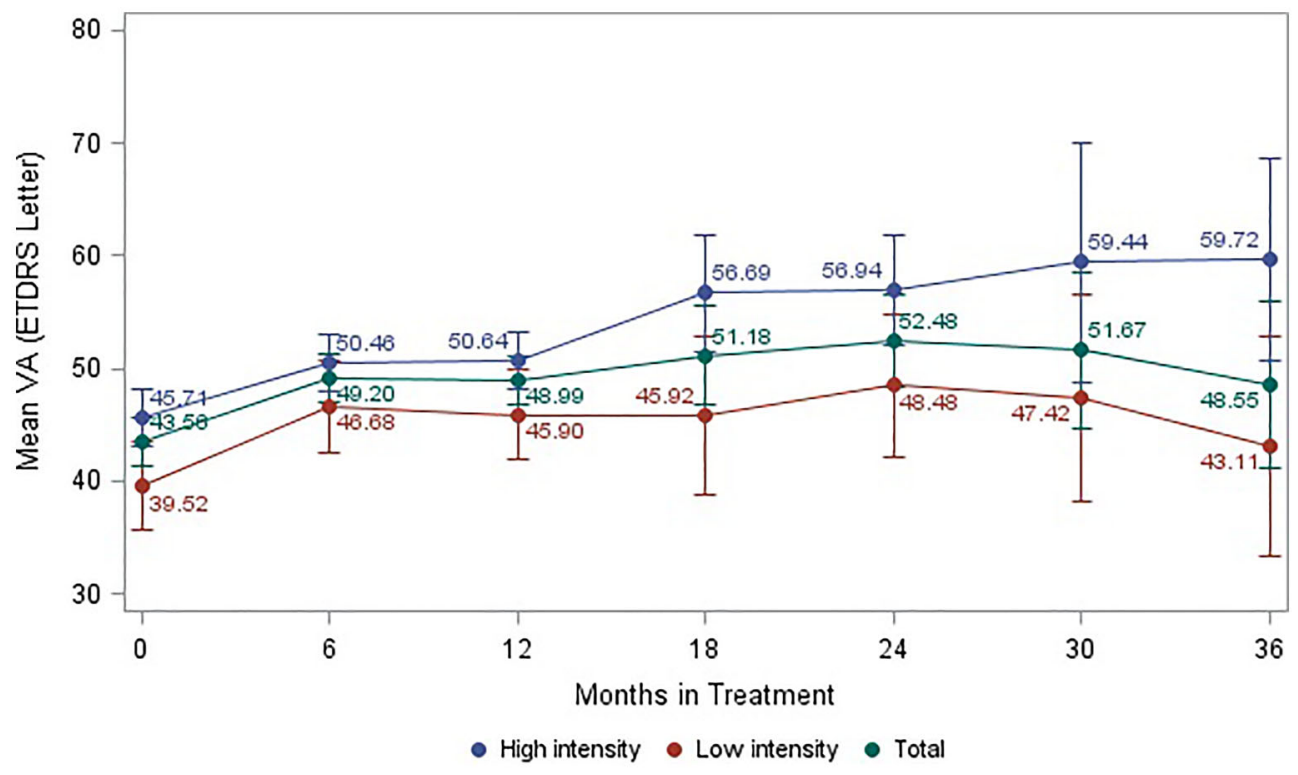

Fig. 3 Mean visual acuity (VA) (ETDRS letter) from baseline to month 36 stratified by treatment intensity. High intensity is shown in blue, low intensity in red, and

most $(74.46 \%$ in year $1,51.28 \%$ in year 2 , and 45.24 in year 3 ) had an average interval of injection of $\leq 8$ weeks, which represents a high treatment burden for patients, caregivers, doctors, and hospitals. Furthermore, about $35 \%$ of patients in our study were lost to follow-up, which is one of the key factors of unsuccessful outcomes. According to the literature, the dropout rate in developed countries is lower, resulting in more injections over 3 years of initial treatment and better improvement in long-term patient outcomes [24]. The effect of treatment burden on healthcare systems may be magnified in the context of emerging countries, where national utilities are limited. Another study reported bevacizumab step-therapy outcomes at Vanderbilt Eye Institute (VEI) showing that 27\% of patients who achieved treatment stability on bevacizumab required injections more frequently than the 8-week interval, which was notably less than in our study [25]. This result reflects different practices in treatment decision factors, for example, functional outcomes or disease activities as resulted in our study. In addition, patients in our study had higher prevalence of PCV, which might lead to a more intensive treatment. total in green. Data are represented as mean VA with $95 \%$ confidential interval (CI). Significance: $P \leq 0.05$

The number of injections declined to 3.44 in year 2 and 2.71 in year 3 , while the number of visits decreased to 5.67 in year 2 and 4.93 in year 3 . The reduction in both the number of injections and visits in years 2 and 3 may lead to declining vision at the end of year 3 in our study. This real-world undertreatment practice pattern is commonly found in many publications and results in poor long-term visual outcomes $[26,27]$. As shown in previous reports, a higher number of injections results in better visual outcomes $[28,29]$. We also found that patients who received high-intensity injections gained vision continuously over 3 years. In contrast to the low-intensity group, a decrease of vision to almost equal to baseline was found at 3 years. Our findings confirm the necessity of a continuous and long-term optimal treatment to maintain the benefits of vision.

Nevertheless, data from the Fight Retinal Blindness Registry demonstrated the magnitude of visual gain decreased over time. Patients begin to lose vision ( -2.7 letters) in year 7 despite receiving 5-6 injections every year [30]. This finding may represent the natural course of AMD, which often ends with fibrotic scar formation and atrophy of retinal tissue. However, 


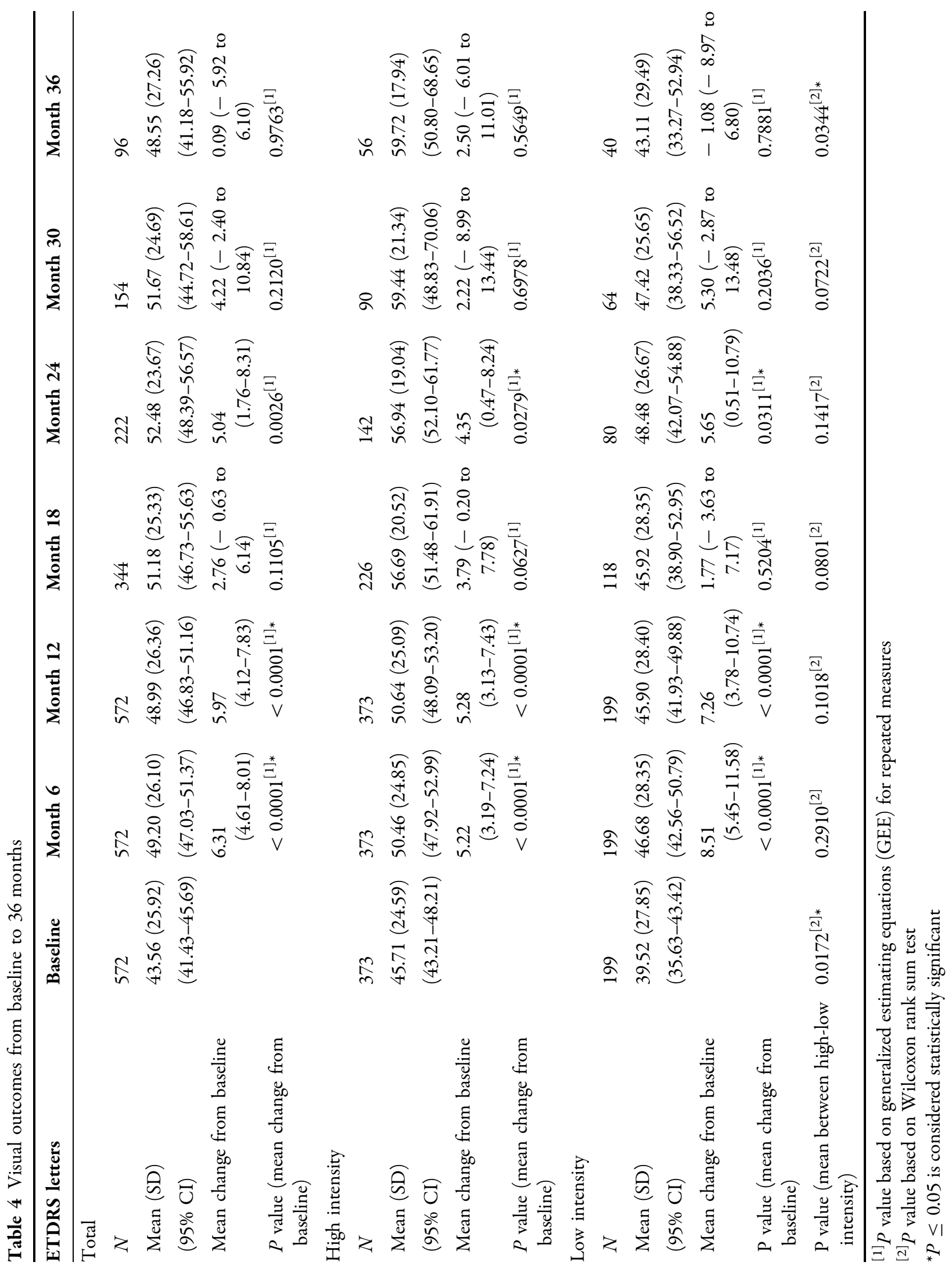




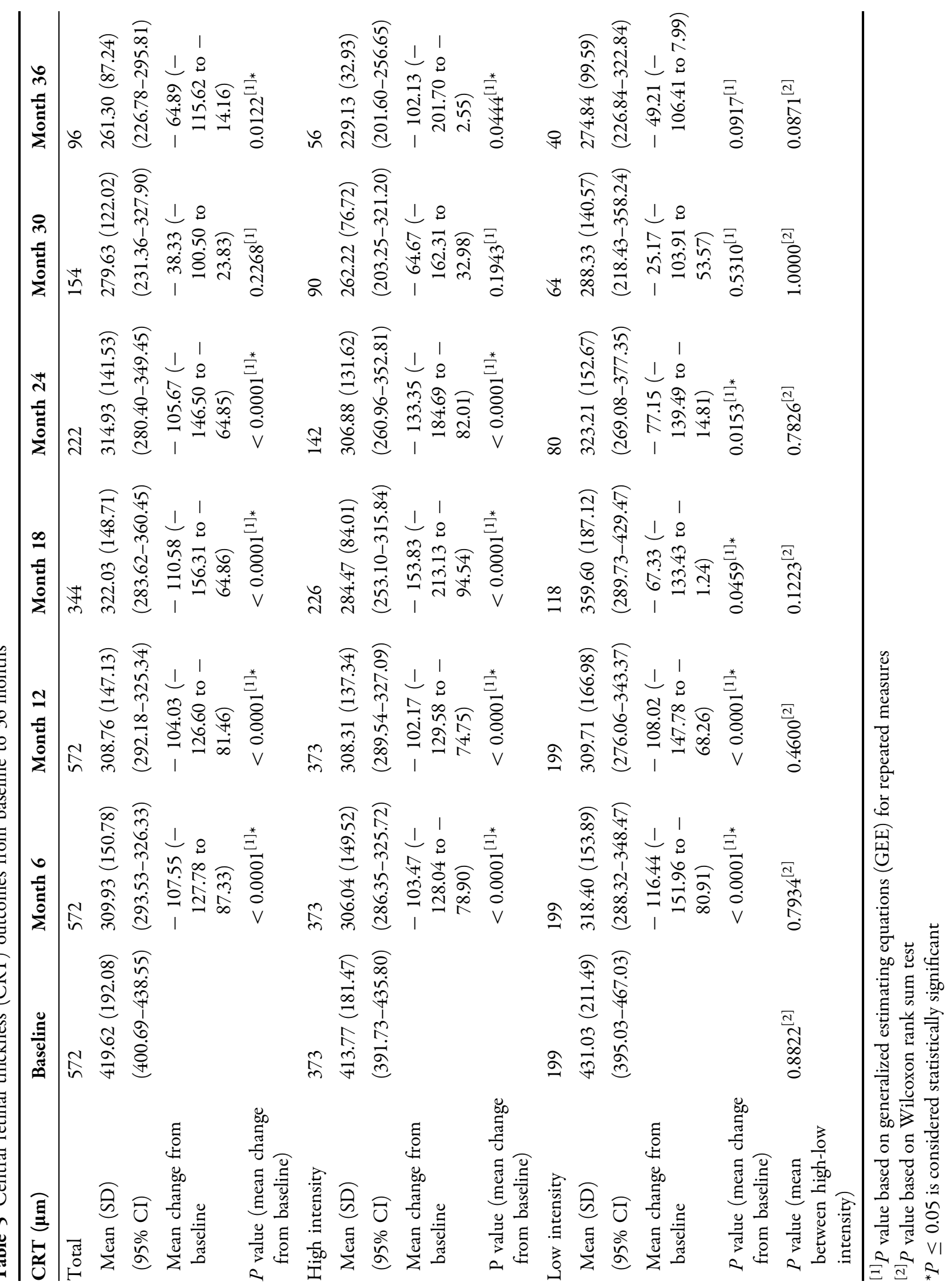




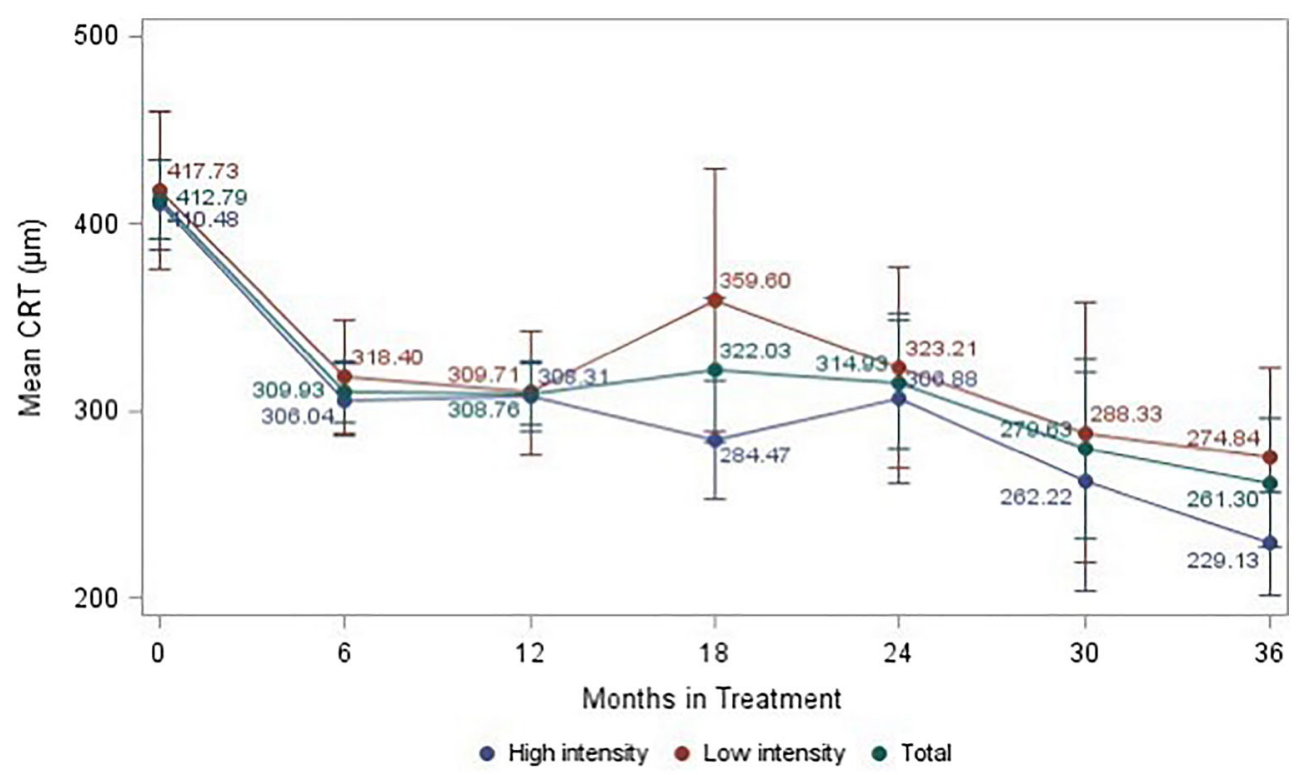

Fig. 4 Mean central retinal thickness (CRT) from baseline to month 36 stratified by treatment intensity. High intensity is shown in blue, low intensity in red, and

total in green. Data are represented as mean CRT in microns $(\mu \mathrm{m})$ with $95 \%$ confidential interval $(\mathrm{CI})$

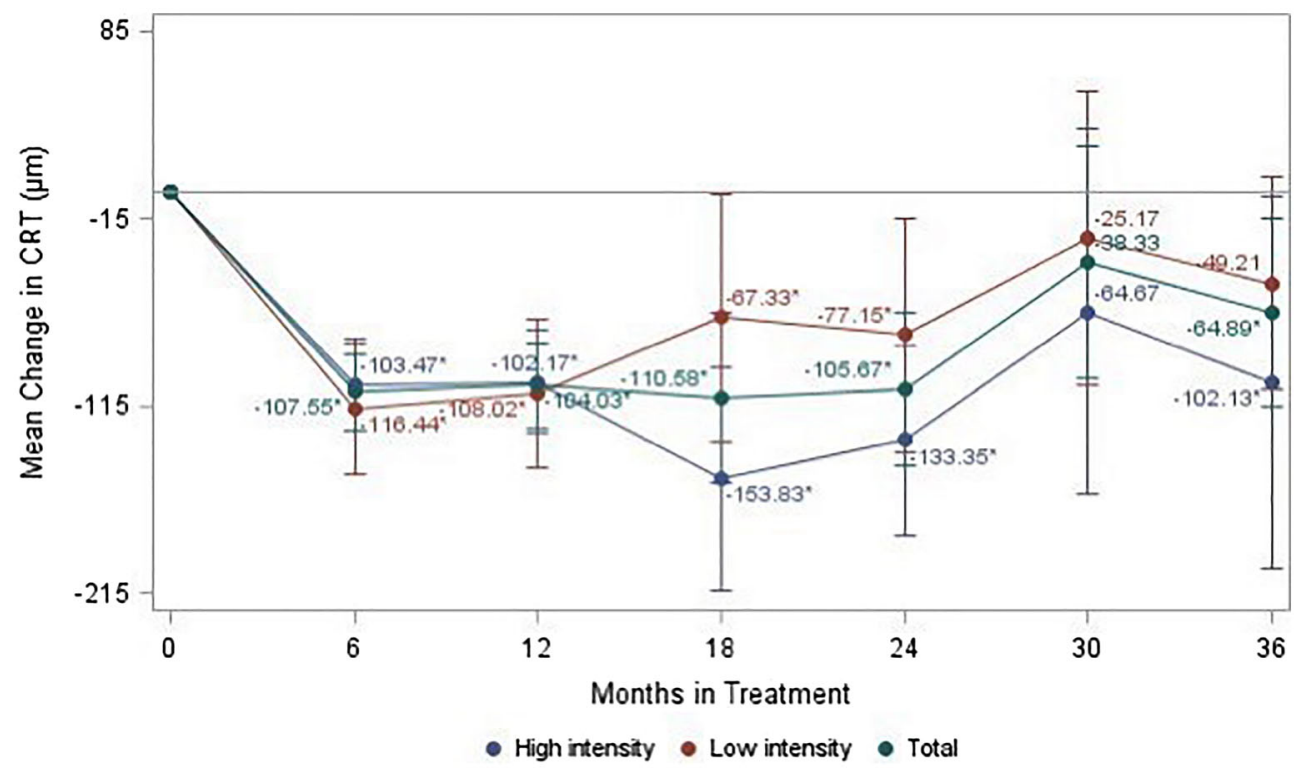

Fig. 5 Mean change in central retinal thickness (CRT) from baseline to month 36 stratified by treatment intensity. High intensity is shown in blue, low intensity in red, and total in green. Data are represented as mean

without an adequate treatment in prior years, patients may suffer a greater and earlier vision loss than that presented in the study.
CRT in microns $(\mu \mathrm{m})$ with $95 \%$ confidential interval (CI). Significance: $P \leq 0.05$. The mean change with $95 \%$ $\mathrm{CI}$ was calculated based on generalized estimating equations (GEEs)

Almost half of our patients (45.98\%) still had disease activity at the end of year 1 . This finding represents the sub-optimal treatment of nAMD 


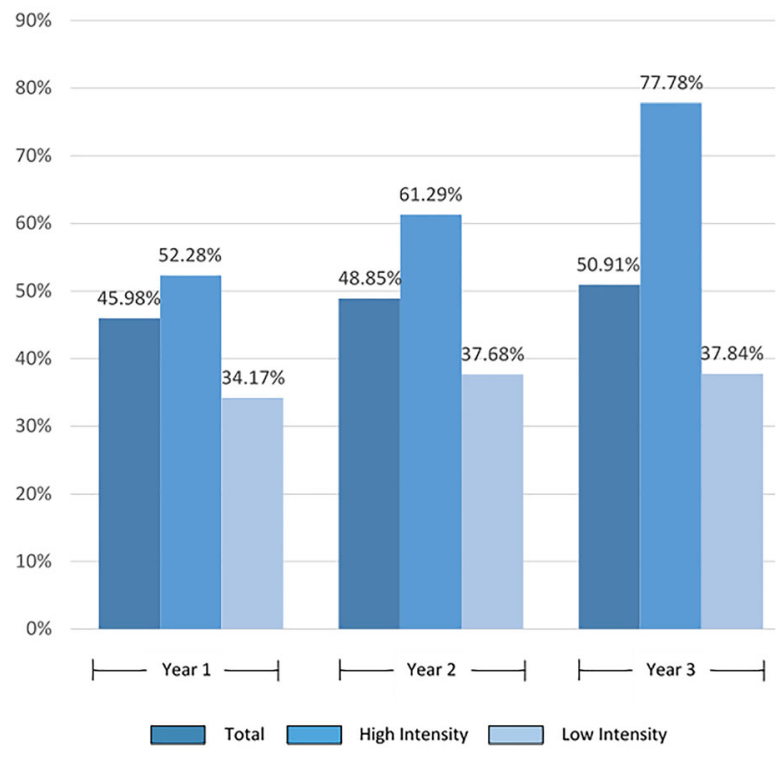

Fig. 6 Presence of disease activity at years 1,2, and 3. Data are represented as the percentage (\%) of patients with disease activity in low-intensity group, high-intensity group, and total

in real-life practice. Data from previous reports revealed that visual outcomes in real-world studies were less than in clinical trials according to a low number of treatments [18-21]. In addition to undertreatment, our study has demonstrated additional probabilities and possibilities. In the high-intensity cohort, patients received three loading injections and at least five injections every year; more than half of them $(52.28 \%)$ still had disease activity at year 1 and the disease activity increased more than three-fourths $(77.78 \%)$ in year 3 . This finding may imply the inadequate response to the existing anti-VEGF agents, which was bevacizumab in the majority of patients rather than inadequacy of injection.

In real-world practice, most retinal specialists in our country prefer to switch medication in nAMD patients who have fluid persistent on OCT after receiving at least 3-monthly injections of bevacizumab. However, only patients with a specific reimbursement scheme can switch to an expensive on-label anti-VEGF medication or PDT. We found almost half of our patients $(46.50 \%)$ received bevacizumab without switching. Continuing ineffective treatment may result in unfavorable long-term outcomes.

The presence of disease activity was detected in an estimated half of patients at the index year of our study. The fluid biomarker on OCT

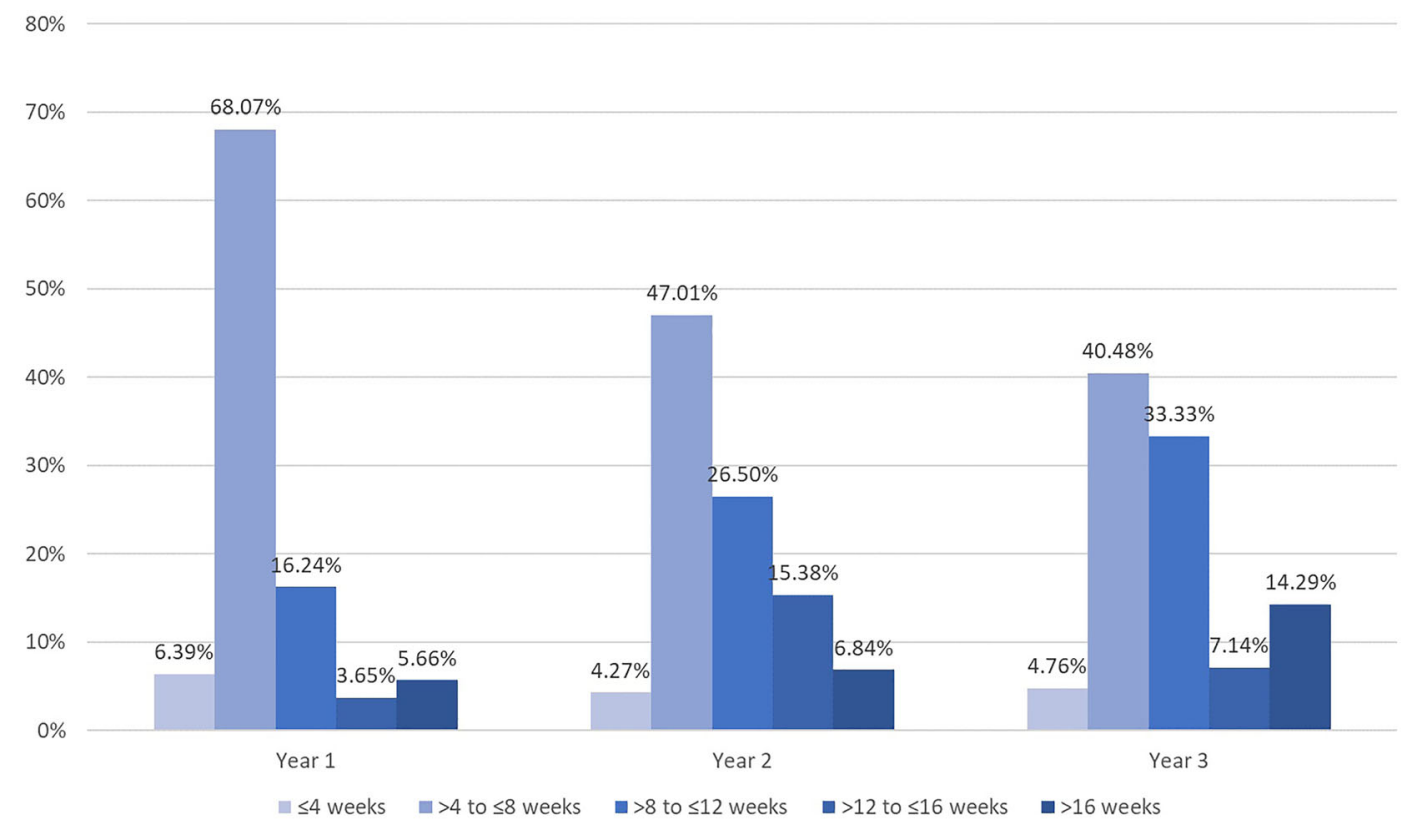

Fig. 7 Mean injection interval at years 1, 2, and 3. Data are represented as the percentage (\%) of patients in each of the five different time intervals within each year 
images showed diverse effects on vision. SRF was indicated to be a positive predictive factor, and unlike IRF, it showed a negative impact on VA in previous studies $[31,32]$. The FLUID study demonstrated that at month 24 the visual acuity in patients in which the treatment protocol allowed SRF as a positive predictor was comparable to those with a treatment protocol that aimed to resolve SRF completely [33]. However, investigations using automated fluid quantification based on artificial intelligence showed no quantitative difference between the two treatment arms during the study period [34]. Nevertheless, the long-term outcome needs to be explored. The effect of fluids on visual outcome was observed in year 3 in our study. This finding may imply the negative effect of longstanding fluids on vision in a realworld situation.

The proportion of patients having fluids on OCT was greater in the high-intensity group than in the low intensity. This finding confirms that treatment consideration in our study was driven by disease activity, like the treat-andextend regimen. However, the overall number of patients having disease activity was high and increased over time. These data represent inadequacy of treatment rather than what was expected from the treatment protocol. Particularly in the low-intensity group, disease activity was observed in more than one-third of our patients over the study period (from $34.17 \%$ in year 1 to $37.84 \%$ in year 3 ). These patients received insufficient treatments, which resulted in significantly declining vision at year 3 .

In our study, $57.87 \%$ of patients were diagnosed with PCV, which is commonly found in Thai patients presenting with exudative CNV [8]. Treatments of PCV are quite similar to nAMD. The landmark study, EVEREST II, showed better outcomes in combination therapy with ranibizumab and PDT for visual gain and regression of polyp lesions [10]. However, results of the PLANET study suggested the treatment of PCV to be effective with aflibercept monotherapy [9]. The benefits of bevacizumab in the treatment PCV have been demonstrated previously $[35,36]$.

Previous real-world study in the Asian population showed an impressive visual improvement at 1 year after treatment. They found that about $30 \%$ of all patients and $50 \%$ of PCV patients received a combination therapy with PDT [29], whereas only $9.09 \%$ of our patients and $15.71 \%$ of PCV patients were exposed to at least one PDT treatment. This means that most patients in the TOWER study received anti-VEGF monotherapy. In our study, only PCV patients who did not respond to antVEGF therapy or having polyps predominantly were considered to use PDT as a combination therapy. This may conclude that treatment of PCV with anti-VEGF monotherapy in the context of real-world practice can improve vision.

Our study demonstrated the outcomes of Asian nAMD treatments in the context of the real-world setting under national health policy of Medicare reimbursement, which showed different outcomes to previous studies [20, 21]. The step treatment initiating with bevacizumab showed improvement in both visual and anatomical outcomes. Moreover, our study may represent real-world outcomes of bevacizumab monotherapy in a large population of $\mathrm{PCV}$ patients that to our knowledge have never been shown in previous studies.

Our study had several limitations. Undefined diagnostic criteria and treatment protocol as well as interpretation of OCT images without a central reading center resulted in inhomogeneous data. Visual measurements are usually not fully corrected in routine clinical practice. Lastly, inclusion of patients with initial VA may have included eyes with severe structural damage at the fovea and have very limited scope for improvement.

\section{CONCLUSION}

In summary, our study established the effectiveness and safety of anti-VEGF in nAMD treatment. Although nAMD patients in Thailand can access anti-VEGF therapy effortlessly, the number of injections declined continuously leading to loss of benefit in year 3. Our data confirm several unmet needs in real-world practice. The impact of undertreatment resulted in unfavorable long-term outcomes. The importance of long-lasting constant treatment 
should be discussed and considered among patients and clinicians. Lastly, repeated injection frequently causes a burden for healthcare systems. Novel treatment modalities with higher potency and longer action may help to reduce current unmet needs.

\section{ACKNOWLEDGEMENTS}

The authors thank Dr. Rawi Jongpipatchai, Dr. Atasit Rojanasakul, Dr. Nattawat Asawaworarit, Dr. Anyarak Amornpetchsathaporn, Dr. Warisara Pattanapongpaiboon, and Dr. Kun Tipparut as sub-investigators and Thunyaporn Keawgum as a study coordinator. The authors also thank Tipaporn Pongmesa, Punthita Sakuntanaga, and Nattaporn Piensaknusorn for their support in study process facilitation.

Funding. This study was funded by Novartis (Thailand) Limited. The journal's Rapid Service fees were funded by Novartis (Thailand) Limited.

Authorship. All authors meet the International Committee of Medical Journal Editors (ICMJE) criteria for authorship for this manuscript, take responsibility for the integrity of the work as a whole, and have given final approval for the version to be published.

Author Contributions. All authors performed the data analysis, interpretation of the results. All authors contributed to the final version of the manuscript. Dr. Somanus Thoongsuwan performed critical revision of the manuscript. All authors read and approved the final manuscript.

Disclosures. Dr. Prut Hanutsaha and Dr. Somanus Thoongsuwan are consultants for Bayer, Novartis and Roche. They are the board committee of Thai Retina Society. Dr. Paisan Ruamviboonsuk is a consultant for Novartis and Roche. He works as scientific secretary of AsiaPacific Vitreo-retina Society, vice-president of Asia-Pacific Teleophthalmology Society, council member of Asia-Pacific Academy of
Ophthalmology, secretary-general of ASEAN Ophthalmology Society, and council member of Asia-Pacific Ophthalmology Imaging Society. Dr. Yodpong Chantarasorn is a consultant for Alcon, Bayer, Novartis, and Roche. He works as vice liaison of American Society of Retina Specialists. Dr. Sritatath Vongkulsiri is a consultant for Bayer and Roche. Pavinee Kungwanpongpun is a medical lead at Novartis (Thailand) Limited.

Compliance with Ethics Guidelines. The study was approved by the ethics committee or institutional review board at each participating center and conducted in accordance with the Declaration of Helsinki. Patients' informed consent was exempted because of the retrospective nature of the study and use of unidentified retinal images and clinical data. The ethics committee or institutional review board at each participating center included: Protection Unit, Faculty of Medicine Siriraj Hospital, Mahidol University (Si 851/2020), Ethics Committees on Researches Involving Human Subjects Rajavithi Hospital (221/2563), Institutional Review Board, Faculty of Medicine Vajira Hospital (CREC010/2020), Human Research Ethics committees, Faculty of Medicine Ramathibodi Hospital, Mahidol University (CREC095/2020) and The Institutional Review Board, and Royal Thai Army Medical Department (IRBRTA0358/2021).

Data Availability. The datasets generated during and/or analyzed during the current study are available from the corresponding author on reasonable request.

Open Access. This article is licensed under a Creative Commons Attribution-NonCommercial 4.0 International License, which permits any non-commercial use, sharing, adaptation, distribution and reproduction in any medium or format, as long as you give appropriate credit to the original author(s) and the source, provide a link to the Creative Commons licence, and indicate if changes were made. The images or other third party material in this article are included in the article's Creative Commons licence, unless indicated 
otherwise in a credit line to the material. If material is not included in the article's Creative Commons licence and your intended use is not permitted by statutory regulation or exceeds the permitted use, you will need to obtain permission directly from the copyright holder. To view a copy of this licence, visit http:// creativecommons.org/licenses/by-nc/4.0/.

\section{REFERENCES}

1. Blindness GBD, Vision Impairment C, Vision Loss Expert Group of the Global Burden of Disease S. Causes of blindness and vision impairment in 2020 and trends over 30 years, and prevalence of avoidable blindness in relation to VISION 2020: the Right to Sight: an analysis for the Global Burden of Disease Study. Lancet Glob Health. 2021;9(2):e144-60.

2. Brown DM, Michels M, Kaiser PK, et al. Ranibizumab versus verteporfin photodynamic therapy for neovascular age-related macular degeneration: twoyear results of the ANCHOR study. Ophthalmology. 2009;116(1):57-65.

3. Kaiser PK, Brown DM, Zhang K, et al. Ranibizumab for predominantly classic neovascular age-related macular degeneration: subgroup analysis of firstyear ANCHOR results. Am J Ophthalmol. 2007;144(6):850-7.

4. Bressler NM, Chang TS, Fine JT, Dolan CM, Ward J, Anti VAftToPCCNiA-RMDRG. Improved vision-related function after ranibizumab vs photodynamic therapy: a randomized clinical trial. Arch Ophthalmol. 2009;127(1):13-21.

5. Wykoff CC, Ou WC, Brown DM, et al. Randomized trial of treat-and-extend versus monthly dosing for neovascular age-related macular degeneration: 2-year results of the TREX-AMD study. Ophthalmol Retina. 2017;1(4):314-21.

6. Ohji M, Takahashi K, Okada AA, et al. Efficacy and safety of intravitreal aflibercept treat-and-extend regimens in exudative age-related macular degeneration: 52- and 96-week findings from ALTAIR: a randomized controlled trial. Adv Ther. 2020;37(3): 1173-87.

7. Wong CW, Yanagi Y, Lee WK, et al. Age-related macular degeneration and polypoidal choroidal vasculopathy in Asians. Prog Retin Eye Res. 2016;53:107-39.

8. Bhoomibunchoo C, Yospaiboon Y, Thoongsuwan S, et al. Idiopathic polypoidal choroidal vasculopathy in Thai patients with clinical and angiographic choroidal neovascularization. Clin Ophthalmol. 2017;11:317-22.

9. Lee WK, Iida T, Ogura Y, et al. Efficacy and safety of intravitreal aflibercept for polypoidal choroidal vasculopathy in the PLANET study: a randomized clinical trial. JAMA Ophthalmol. 2018;136(7): 786-93.

10. Lim TH, Lai TYY, Takahashi K, et al. Comparison of ranibizumab with or without verteporfin photodynamic therapy for polypoidal choroidal vasculopathy: the EVEREST II randomized clinical trial. JAMA Ophthalmol. 2020;138(9):935-42.

11. Kumluang S, Ingsrisawang L, Sangroongruangsri S, et al. A real-world study of effectiveness of intravitreal bevacizumab and ranibizumab injection for treating retinal diseases in Thailand. BMC Ophthalmol. 2019;19:82.

12. Keane PA, Patel PJ, Liakopoulos S, Heussen FM, Sadda SR, Tufail A. Evaluation of age-related macular degeneration with optical coherence tomography. Surv Ophthalmol. 2012;57(5):389-414.

13. Cheung CMG, Lai TYY, Teo K, et al. Polypoidal choroidal vasculopathy: consensus nomenclature and non-indocyanine green angiograph diagnostic criteria from the Asia-Pacific ocular imaging society PCV workgroup. Ophthalmology. 2021;128(3): 443-52.

14. Schmidt-Erfurth U, Chong V, Loewenstein A, et al. Guidelines for the management of neovascular agerelated macular degeneration by the European Society of Retina Specialists (EURETINA). Br J Ophthalmol. 2014;98(9):1144-67.

15. Patel PJ, Devonport H, Sivaprasad S, et al. Aflibercept treatment for neovascular AMD beyond the first year: consensus recommendations by a UK expert roundtable panel, 2017 update. Clin Ophthalmol. 2017;11:1957-66.

16. Cruess AF, Berger A, Colleaux $\mathrm{K}$, et al. Canadian expert consensus: optimal treatment of neovascular age-related macular degeneration. Can J Ophthalmol. 2012;47(3):227-35.

17. Koh A, Lanzetta $\mathrm{P}$, Lee WK, et al. Recommended guidelines for use of intravitreal aflibercept with a treat-and-extend regimen for the management of neovascular age-related macular degeneration in the Asia-Pacific region: report from a consensus panel. Asia Pac J Ophthalmol (Phila). 2017;6(3): 296-302.

18. Mehta H, Tufail A, Daien V, et al. Real-world outcomes in patients with neovascular age-related macular degeneration treated with intravitreal 
vascular endothelial growth factor inhibitors. Prog Retin Eye Res. 2018;65:127-46.

19. Kim LN, Mehta H, Barthelmes D, Nguyen V, Gillies MC. Metaanalysis of real-world outcomes of intravitreal ranibizumab for the treatment of neovascular age-related macular degeneration. Retina. 2016;36(8):1418-31.

20. Holz FG, Tadayoni R, Beatty S, et al. Multi-country real-life experience of anti-vascular endothelial growth factor therapy for wet age-related macular degeneration. Br J Ophthalmol. 2015;99(2):220-6.

21. Writing Committee for the UKA-RMDEMRUG. The neovascular age-related macular degeneration database: multicenter study of 92976 ranibizumab injections: report 1: visual acuity. Ophthalmol. 2014;121(5):1092-101.

22. Mehta H, Kim LN, Mathis T, et al. Trends in RealWorld Neovascular AMD treatment outcomes in the UK. Clin Ophthalmol. 2020;14:3331-42.

23. Papadopoulos N, Martin J, Ruan Q, et al. Binding and neutralization of vascular endothelial growth factor (VEGF) and related ligands by VEGF Trap, ranibizumab and bevacizumab. Angiogenes. 2012;15(2):171-85.

24. Verbraak FD, Ponsioen DL, Tigchelaar-Besling OA, et al. Real-world treatment outcomes of neovascular age-related macular degeneration in the Netherlands. Acta Ophthalmol. 2021;99(6):e884-92.

25. Siktberg J, Kim SJ, Patel S. Efficacy of avastin steptherapy for age-related macular degeneration. Investig Ophthalmol Vis Sci. 2020;61(7): 4197-4197.

26. Rofagha S, Bhisitkul RB, Boyer DS, Sadda SR, Zhang $\mathrm{K}$, Group S-US. Seven-year outcomes in ranibizumab-treated patients in ANCHOR, MARINA, and HORIZON: a multicenter cohort study (SEVEN-UP). Ophthalmology. 2013;120(11):2292-9.

27. Mones J, Singh RP, Bandello F, Souied E, Liu X, Gale R. Undertreatment of neovascular age-related macular degeneration after 10 years of anti-vascular endothelial growth factor therapy in the real world: the need for a change of mindset. Ophthalmologica. 2020;243(1):1-8.
28. Holz FG, Tadayoni R, Beatty S, et al. Key drivers of visual acuity gains in neovascular age-related macular degeneration in real life: findings from the AURA study. $\mathrm{Br} \mathrm{J}$ Ophthalmol. 2016;100(12): 1623-8.

29. Fenner BJ, Ting DSW, Tan ACS, et al. Real-world treatment outcomes of age-related macular degeneration and polypoidal choroidal vasculopathy in Asians. Ophthalmol Retina. 2020;4(4):403-14.

30. Gillies MC, Campain A, Barthelmes D, et al. Longterm outcomes of treatment of neovascular age-related macular degeneration: data from an observational study. Ophthalmology. 2015;122(9): 1837-45.

31. Sharma S, Toth CA, Daniel E, et al. Macular morphology and visual acuity in the second year of the comparison of age-related macular degeneration treatments trials. Ophthalmol. 2016;123(4):865-75.

32. Waldstein SM, Simader C, Staurenghi G, et al. Morphology and visual acuity in aflibercept and ranibizumab therapy for neovascular age-related macular degeneration in the VIEW trials. Ophthalmol. 2016;123(7):1521-9.

33. Guymer RH, Markey CM, McAllister IL, et al. Tolerating subretinal fluid in neovascular age-related macular degeneration treated with ranibizumab using a treat-and-extend regimen: FLUID study 24-month results. Ophthalmology. 2019;126(5): 723-34.

34. Reiter GS, Grechenig C, Vogl WD, et al. Analysis of fluid volume and its impact on visual acuity in the fluid study as quantified with deep learning. Retina. 2021;41(6):1318-28.

35. Wakabayashi T, Gomi F, Sawa M, Tsujikawa M, Nishida K. Intravitreal bevacizumab for exudative branching vascular networks in polypoidal choroidal vasculopathy. Br J Ophthalmol. 2012;96(3): 394-9.

36. Lee SY, Kim JG, Joe SG, Chung H, Yoon YH. The therapeutic effects of bevacizumab in patients with polypoidal choroidal vasculopathy. Korean J Ophthalmol. 2008;22(2):92-9. 